\title{
Diverse Effects of Conditioned Threat Stimuli on Behavior
}

\author{
Justin M. Moscarello ${ }^{1}$ AND Joseph LeDoux ${ }^{1,2}$ \\ ${ }^{1}$ Center for Neural Science, New York University, New York, New York 10003 \\ ${ }^{2}$ Emotional Brain Institute, Nathan Klein Institute, Orangeburg, New York 10962 \\ Correspondence:ledoux@cns.nyu.edu
}

\begin{abstract}
Aversive Pavlovian memory coordinates the defensive behavioral response to learned threats. The amygdala is a key locus for the acquisition and storage of aversive associations. Information about conditioned and unconditioned stimuli converge in the lateral amygdala, which is a hot spot for the plasticity induced by associative learning. Central amygdala uses Pavlovian memory to coordinate the conditioned reaction to an aversive conditioned stimulus. Aversive associations can also access the brain networks of instrumental action. The offset of an aversive conditioned stimulus can reinforce behavior, recruiting a pathway that includes the lateral and basal amygdala, as opposed to the lateral and central amygdala circuit for Pavlovian reactions. Aversive conditioned stimuli can also modulate ongoing behavior, suppressing appetitive actions and facilitating aversive actions. Facilitation depends on an amygdalar network involving the lateral and central, as well as medial, nuclei. Thus, aversive Pavlovian memory has wide-reaching effects on defensive behavior, coordinating reactive to active responses to environmental threats.
\end{abstract}

Innate and learned threats activate defensive circuits in the brain (Fanselow 1994; Gross and Canteras 2012; LeDoux 2012). In people with fear/anxiety disorders, these mechanisms can be dysregulated, resulting in hypersensitive threat detection and exaggerated and prolonged defensive responses (Charney 2004; Milad and Quirk 2012; Parsons and Ressler 2013). Understanding the brain mechanisms underlying adaptive and pathological reactions to threats is important.

Much work on circuits that detect and respond to threats has been done in the context of aversive Pavlovian conditioning, a procedure in which a biologically neutral conditioned stimulus (CS) is paired with a noxious unconditioned stimulus (US). Thereafter, the CS has the ability to elicit innate defensive reactions, such as freezing behavior (Blanchard and Blanchard 1969), and supporting physiological responses (Kapp et al. 1979; LeDoux et al. 1982), and to potentiate reflexes such as startle (Davis 1992). This form of associative learning is most commonly known as fear conditioning, but has also been called threat conditioning (LeDoux 2014). Here, we use the term Pavlovian threat conditioning (PTC; Fig. 1). PTC is useable across a wide range of species, from invertebrates (Carew et al. 1981; Glanzman 2010) to vertebrates (Davis 1992; Fanselow 1994; LeDoux 2000, 2012), including humans (Ohman and Mineka 2001; Phelps 2006). Further, the fact that changes in systems level functions are correlated with symptomatology in people with fear/anxiety disorders (Rauch et al. 2006; Liberzon and Sripada 2008), and that treatments that reduce symptoms in animals can also reduce symptoms in humans (Milad and Quirk 2012; Parsons and Ressler 2013), gives PTC a documented clinical relevance.

\section{THE LATERAL AMYGDALA ACQUIRES AND STORES AVERSIVE PAVLOVIAN MEMORY}

Decades of research show that the rodent amygdala is an important site for the acquisition and storage of aversive Pavlovian memory (for review, see Fanselow 1994; LeDoux 2000, 2012; Johansen et al. 2011). The amygdala is a complex network of interconnected subnuclei, which are thought to play distinct roles in PTC (Fig. 2; Pitkänen et al. 1997). The lateral amygdala (LA) receives convergent input from CS and US pathways (LeDoux et al. 1990), whereas the central nucleus of the amygdala (CeA) sends long-range projections to the brainstem effector sites that mediate conditioned reactions (LeDoux et al. 1988; Viviani et al. 2011). Information about aversive associations proceeds through the amygdala in a serial fashion. LA contacts the lateral subregion of $\mathrm{CeA}$, which communicates with output neurons in medial CeA through a complex, disinhibitory microcircuit (Ciocchi et al. 2010; Li et al. 2013). In addition, LA and CeA are indirectly connected via pathways involving the basal nucleus, as well as the intercalated cell masses (Pitkänen et al. 1997). The data described below support a model in which LA encodes aversive associations, whereas CeA receives associative information and uses it to control the behavioral and physiological outputs of Pavlovian memory.

Because auditory PTC brings conditioned behavior under the control of a tone CS, the search for learningrelated plasticity has focused on LA and its auditory inputs (LeDoux 2000; Maren and Quirk 2004). Pavlovian conditioning modifies CS-evoked activity in LA, as well as in the tertiary auditory cortex and medial geniculate nucleus of the thalamus (MGN), both of which project directly to LA (Quirk et al. 1997; Maren et al. 2001). 


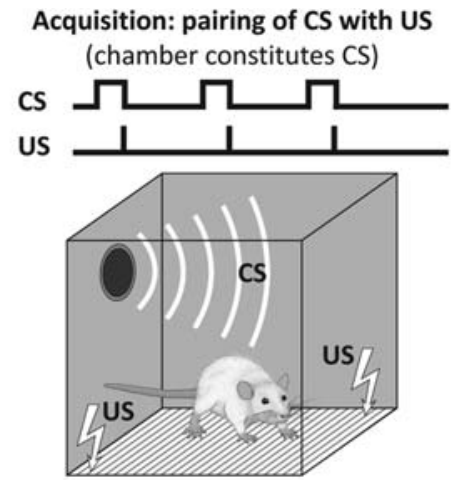

Cued CS Test: exposure to the CS alone

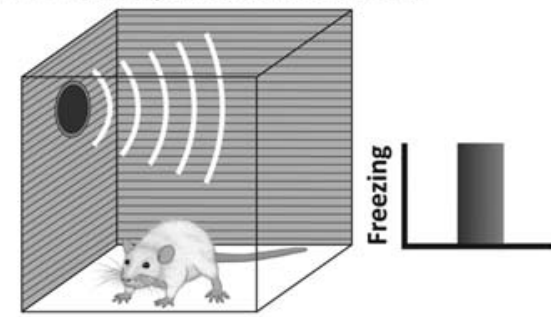

Control CS Test: exposure to a tone not paired with US

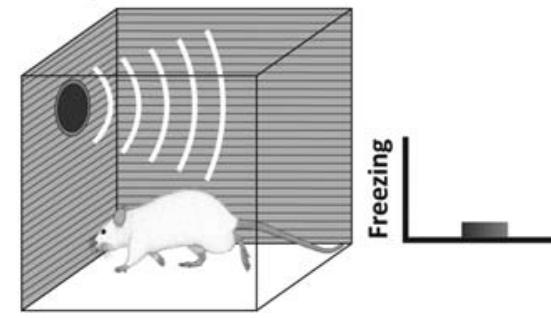

Figure 1. Pavlovian threat conditioning. This form of associative learning occurs when a previously neutral tone CS is paired with a footshock US. When the CS is presented later in the absence of the US, it evokes behavioral and physiological conditioned reactions, including freezing and changes in heart rate. These effects are not elicited by a CS that is not paired with the US.

Although these observations suggest that a widely distributed network encodes aversive associations, it is important to note that LA mediates plasticity in upstream auditory regions. CS-responsive cells in auditory cortex develop conditioned enhancements more slowly than CSresponsive cells in LA (Quirk et al. 1997), and LA lesions alter learning-related modifications in cortical activity (Armony et al. 1998). Inactivation of the basolateral complex, which includes LA, prevents conditioned neuronal responses from forming in MGN (Maren et al. 2001). It seems that feedback from the amygdala is required to maintain normal plasticity in auditory regions, suggesting a distributed representation that depends on encoding by LA neurons (Maren and Quirk 2004).

LA contains multimodal neurons that respond to both tone and shock (Romanski et al. 1993), creating a cellular substrate for the integration of CS and US information. During conditioning, enhancements in CS-evoked neuronal activity precede learned changes in behavior, high- lighting the role of LA plasticity in memory formation (Quirk et al. 1995; Repa et al. 2001). Spiking also synchronizes across CS-responsive cells (Quirk et al. 1995; Paré and Collins 2000), suggesting that aversive associations are encoded by the rate and rhythm of action potentials in LA (Maren and Quirk 2004). The associative nature of these neural codes is further shown by the fact that conditioned enhancements in LA cell firing move through a "hill climbing" process that parallels the acquisition of behavioral reactions to the CS (Repa et al. 2001).

In addition to initial conditioning, extinction training has predictable effects on the activity of responsive LA neurons. This inhibitory form of learning attenuates CSevoked activity in the dorsal LA cells that undergo rapid modifications during acquisition (Repa et al. 2001). Thus, cells in the dorsal tip of LA track changes in CS valence with corresponding changes in firing rate. In contrast, a relatively ventral subpopulation of CS-responsive LA neurons continues to display conditioned enhancements in spiking even after extinction training (Repa et al. 2001). These cells may carry an indelible element of associative memory that allows for the return of conditioned behavior following extinction. Together, these data illustrate how aversive Pavlovian memories are encoded by complex patterns of activity distributed over LA neurons participating in the memory trace.

On a synaptic level, it is theorized that conditioned modifications in LA spiking are supported by Hebbian mechanisms (Blair et al. 2001, 2003; Johansen et al. 2011). Hebb proposed a "fire together, wire together" principle by which a synapse is strengthened through concurrent activity in pre- and postsynaptic cells (Hebb 1949), suggesting a hypothetical means by which LA neurons can integrate CS and US information (Blair et al. 2001, 2003). Before Pavlovian learning, auditory synapses only weakly depolarize LA neurons. However, when inputs carrying the auditory CS occur simultaneously with robust depolarization evoked by the US, auditory synapses are strengthened through the temporal coincidence of presynaptic stimulation and postsynaptic activity. The resulting changes in synapse strength allow CS inputs to drive neuronal responses in LA, thus reactivating associative information even in the absence of the US.

NMDA receptors (NMDARs) are thought to play a key role in this Hebbian process. Postsynaptic depolarization dislodges magnesium ions from NMDARs, allowing these receptors to pass calcium when bound by glutamate (Malenka and Nicoll 1999). As such, NMDARs at auditory synapses can detect the cooccurrence of presynaptic glutamate release caused by the CS and postsynaptic depolarization caused by the US (Blair et al. 2001, 2003). The resulting influx of calcium triggers important molecular signaling cascades that underpin plasticity and memory formation (Johansen et al. 2011). This model is supported by pharmacological experiments demonstrating that intra-LA infusion of an NMDA antagonist prevents PTC (Maren et al. 1996; Rodrigues et al. 2001), as well as by in vitro experiments demonstrating that NMDARs are necessary for long-term potentiation at auditory synapses in LA (Bauer et al. 2002). 


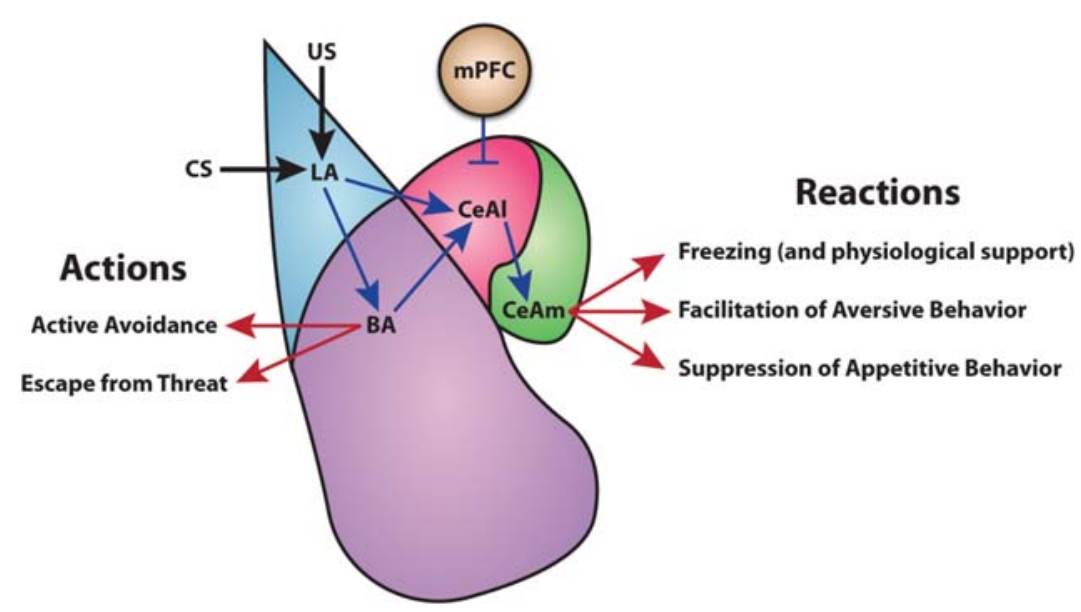

Figure 2. Role of the amygdala in aversive Pavlovian memory. CS and US converge in the lateral amygdala (LA). CS-evoked actions and reactions depend on different pathways emanating from LA. Reactions, such as freezing, occur when associative information is passed through the lateral subdivision of the central amygdala (CeA), before exiting via the medial CeA. The CS can also facilitate or suppress ongoing actions via this amygdalar pathway, though facilitation and suppression likely involve different CeA target regions. Actions, such as avoidance and escape from threat, engage the basal amygdala, but not CeA.

Along with NMDAR-dependent Hebbian mechanisms, additional factors are required for LA neurons to encode aversive Pavlovian memory, such as release of the neuromodulator norepinephrine (NE). PTC is prevented by blockade of NE $\beta$-adrenergic receptors ( $\beta$ ARs) in LA (Bush et al. 2010). $\beta$ AR signaling can mediate glutamatergic transmission via intracellular signaling cascades that lead to the phosphorylation of both NMDARs and AMPA glutamate receptors (Raman et al. 1996; Hu et al. 2007), thus regulating glutamatergic neurotransmission in a manner that could directly facilitate Hebbian learning. Other $\beta$ AR-mediated mechanisms include changes in the excitability of LA principle neurons (Faber et al. 2008), as well as the suppression of inhibitory interneurons (Tully et al. 2007; Tully and Bolshakov 2010), both of which could modulate Hebbian changes in synaptic efficacy.

A recent study provides empirical support for the synergistic relationship between NE modulation and Hebbian learning mechanisms. Optogenetic techniques were used to pair an auditory CS with the depolarization of LA principle cells, in lieu of a standard footshock US. Although this treatment produced no learning on its own, combining it with pretraining intra-LA infusions of a BAR agonist produced an aversive association that was measurable the next day (Johansen et al. 2014). Thus, experimenters were able to create an artificial Pavlovian memory with a combination of $\beta$ AR stimulation and an auditory CS reinforced with neuronal activations that mimic the putative effect of shock on LA neurons.

In summary, LA is a key site for the plasticity underpinning learned associations between an auditory CS and an aversive US. Aversive Pavlovian memory is encoded by the rate and rhythm of action potentials in CS-responsive LA neurons. These associative modifications in LA cell firing are supported by alterations in synaptic efficacy, which involve the complex dialogue between genome and synapse that underpins the storage of information by the nervous system (Kandel 1997; Johansen et al. 2011).

\section{THE CENTRAL AMYGDALA CONTROLS BEHAVIORAL AND PHYSIOLOGICAL REACTIONS TO THE CS}

$\mathrm{CeA}$ is an amygdalar output region that projects to a variety of structures mediating dissociable aspects of the response to an aversive CS (LeDoux et al. 1988). Freezing is the most commonly used readout of Pavlovian memory, though conditioned reactions also include changes in heart rate, respiration, and the hormonal milieu of the blood (LeDoux et al. 1988; Sullivan et al. 2004; Viviani et al. 2011). This constellation of behavioral and physiological responses is encoded in the activity of $\mathrm{CeA}$ microcircuits.

Plasticity in CeA facilitates the serial progression of information from LA, thus translating aversive associations into conditioned behavior. Inactivation of the lateral subdivision of $\mathrm{CeA}$, which receives direct projections from LA (Pitkänen et al. 1997; Li et al. 2013), prevents the acquisition of aversive Pavlovian memory. In contrast, inactivation of medial $\mathrm{CeA}$, which receives no direct input from LA, attenuates the expression of freezing, but has no effect on acquisition (Ciocchi et al. 2010). Electrophysiological studies show that PTC enhances the efficacy of LA synapses on lateral CeA neurons (Li et al. 2013; Penzo et al. 2014), thus creating a conduit by which associative memory can guide CSevoked responses.

In comparison to LA, PTC evokes a combination of inhibition and excitation in different lateral CeA neurons (Duvarci et al. 2011), creating a dynamic interaction between "CS-on" and "CS-off" cell populations (Ciocchi et al. 2010). The "CS-on" population may conform to a group of neurons expressing the somatostatin $\left(\mathrm{SOM}^{+}\right)$ molecule. Optogenetic activation of $\mathrm{SOM}^{+}$cells causes unconditioned freezing ( $\mathrm{Li}$ et al. 2013). The "CS-off" population conforms to a group of neurons expressing the PKC $\delta$ molecule (Ciocchi et al. 2010; Haubensak 
et al. 2010). Optogenetic activation of $\mathrm{PKC}^{+}$cells inhibits conditioned freezing (Haubensak et al. 2010). Consistent with their opposing behavioral functions, these populations mutually inhibit one another (Ciocchi et al. 2010; Haubensak et al. 2010; Li et al. 2013). PTC biases the competition between these groups by selectively enhancing the efficacy of LA synapses on $\mathrm{SOM}^{+}$neurons (Li et al. 2013). Increased activity in $\mathrm{SOM}^{+}$cells leads to the inhibition of $\mathrm{PKC}^{+}$cells, which form inhibitory synapses on medial CeA output neurons (Haubensak et al. 2010; Li et al. 2013). Medial CeA projects to the periaqueductal gray (PAG), an important effector site for freezing behavior (LeDoux et al. 1988; Viviani et al. 2011). PTC evokes a uniform excitation across CS-responsive cells in medial CeA (Duvarci et al. 2011). Thus, plasticity at particular LA synapses in lateral CeA leads to the disinhibition of medial CeA projections to PAG. Although aversive associations are encoded by enhancements in CS-evoked firing in LA, this conditioned activity translates into a complex pattern of excitation and inhibition in the circuitry of the CeA. It has been hypothesized that increased activity in medial CeA output neurons inhibits a network of GABA-ergic cells in PAG, facilitating CS-evoked freezing (Behbehani 1995).

Parallel channels of information through CeA control different elements of the conditioned response. These circuits are modulated by distinct neuropeptidergic inputs and have dissociable outputs from CeA. Lateral CeA contains a population of cells that express oxytocin receptors. Oxytocin agonists excite these neurons, leading to the inhibition of medial CeA neurons that drive CS-evoked freezing (Gozzi et al. 2010; Viviani et al. 2011). Although it is unknown if oxytocin receptor-expressing cells overlap with PKC $\delta$ cells in lateral $\mathrm{CeA}$, they do have the same effect on medial CeA, and thus freezing, when activated. Oxytocin signaling in CeA can alter the behavioral response to the CS, but it has no effect on conditioned changes in heart rate (Viviani and Stoop 2008; Viviani et al. 2011). Conversely, vasopressin signaling in CeA can modulate the circuits for conditioned alterations in cardiac output, but has no effect on pathways that mediate freezing (Huber et al. 2005; Viviani and Stoop 2008). Conditioned changes in cardiac output are mediated by a medial CeA projection to the dorsal vagal complex (Viviani et al. 2011). These cells do not overlap with the medial CeA neurons that project to PAG. Thus, CeA contains distinct, functionally dedicated microcircuits with dissociable modulatory inputs.

In summary, plasticity at LA synapses in lateral CeA biases the competition between mutually inhibitory cell populations, creating the "CS-on" and "CS-off" dynamic that leads to the disinhibition of medial CeA projection neurons and conditioned freezing. The behavioral and physiological reactions to an aversive CS are encoded by parallel circuits in $\mathrm{CeA}$ that are mediated by different neuropeptides. This allows the expression of aversive Pavlovian memory to be guided by modulatory information that is specifically relevant to distinct aspects of the overall reaction to an aversive CS. Finally, the constellation of responses guided by aversive memory are driven by dis- tinct effector regions that receive the long range projections of CeA.

\section{THE AMYGDALA ALSO CONTRIBUTES TO AVERSIVE ACTIONS}

Most work on PTC has focused on how a CS elicits innate defense reactions like freezing or alters startle reflexes. But behavior can be affected in other ways by learned threats. Animals, including humans, use cues associated with danger to prevent aversive outcomes. For example, patients with anxiety disorders often show behaviors that reduce exposure to fear-eliciting stimuli or situations. So-called avoidance responses can be effective coping strategies, but become problematic when they interfere with daily life. In comparison to reactions like freezing, less is known about the neural basis of aversively motivated instrumental actions. Escape from threat (EFT) is particularly useful for exploring how a Pavlovian CS contributes to the acquisition of new instrumental responses (Fig. 3). Although active avoidance paradigms have been more extensively studied (see below), the Pav-
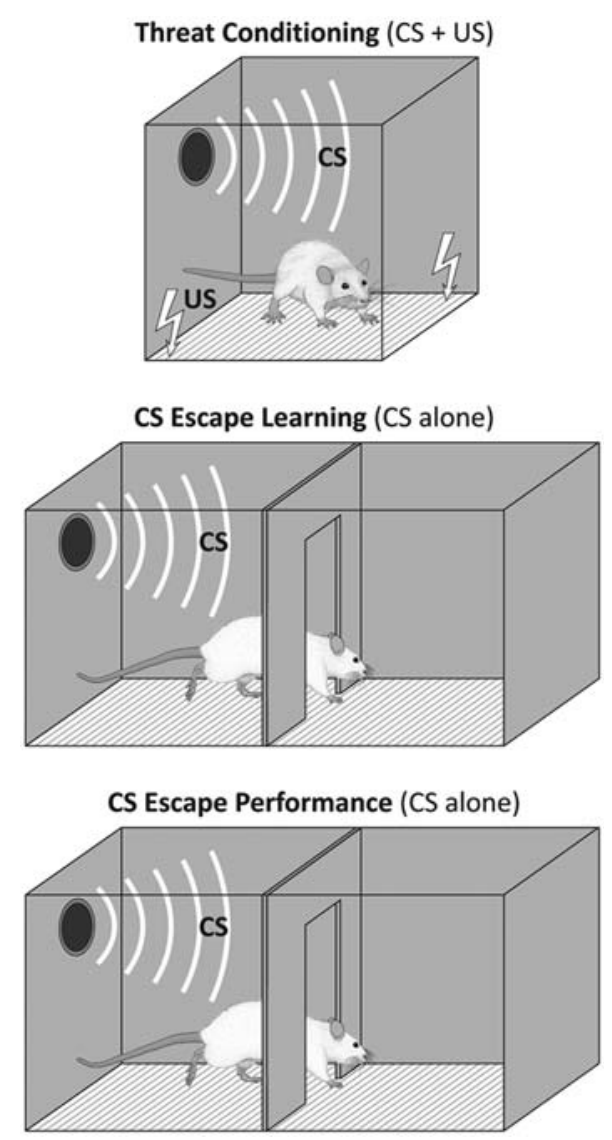

Figure 3. Escape from threat (EFT). Animals first undergo Pavlovian threat conditioning. Then, in a distinct environment, animals learn to inactivate the CS by performing a specific behavior, such as shuttling or rearing. Finally, the animal is given a reinforcement-free test consisting of a single long CS. EFT learning shifts the response to the $\mathrm{CS}$ from reactive to active profile of behavior. 
lovian and instrumental learning components of these tasks are intermixed. EFT breaks learning into discrete phases, allowing the experimenter to isolate the role of different brain regions in the distinct learning processes that contribute to aversively motivated actions. In EFT, the CS-US association is first conditioned in a standard PTC paradigm. Then, in a different context, the animal learns to perform responses that terminate the CS. CS termination is believed to function as conditioned negative reinforcement, in which cessation of a learned cue makes the preceding behavior more likely to reoccur. This section will begin with EFT, to examine the role of amygdalar nuclei in conditioned negative reinforcement, before moving on to active avoidance, which powerfully illustrates the process by which instrumental learning fundamentally reorganizes the responses to a threatening CS.

EFT shows that conditioned negative reinforcement learning depends on the initial formation of an aversive Pavlovian memory. If the CS and US are explicitly unpaired during the PTC phase, animals will not acquire EFT, presumably because the offset of a neutral CS does not reinforce behavior (Cain and LeDoux 2007). Pretraining damage to LA prevents CS-US associations from occurring, and this treatment also prevents the acquisition of EFT (Amorapanth et al. 2000). Plasticity in LA provides an important neural substrate for the learned aversion that motivates active behavior reinforced by CS termination, suggesting that both actions and reactions overlap at this level of amygdalar processing.

The conditioned negative reinforcement phase of EFT learning allows subjects to toggle from reactive to active behavioral states by recruiting distinct pathways emanating from LA (Fig. 2). Because CeA coordinates freezing and other innate reactions to the $\mathrm{CS}$, it is unsurprising that damage to $\mathrm{CeA}$ produces no effects on EFT learning. Instead, pretraining damage to the basal amygdala (BA) attenuates learning during the conditioned negative reinforcement phase of EFT, but has no effect on PTC (Amorapanth et al. 2000). Though no electrophysiological studies have assessed the role of BA neuronal activity in EFT, studies of BA activity during PTC suggest a complex form of processing that may be relevant to conditioned negative reinforcement. BA contains a population of cells that show conditioned enhancements in CS-evoked firing as a result of PTC, comparable to what is observed in LA. However, a distinct group of cells undergo increased spiking to the CS under extinction conditions, when the associated US is omitted (Herry et al. 2008). This suggests that BA can process information about conditioned aversion and forms of learning that mitigate the impact of a threatening CS, both of which are relevant to negative reinforcement and active coping processes.

EFT shows how active and reactive manifestations of aversive Pavlovian memory are encoded by separate pathways originating in LA. The circuits involved in conditioned negative reinforcement are also implicated in signaled active avoidance (SigAA) behavior, which intermixes Pavlovian and instrumental phases of training (Fig. 4). In SigAA, a CS is presented, followed by an aversive US. If, during the CS, the subject performs a particular
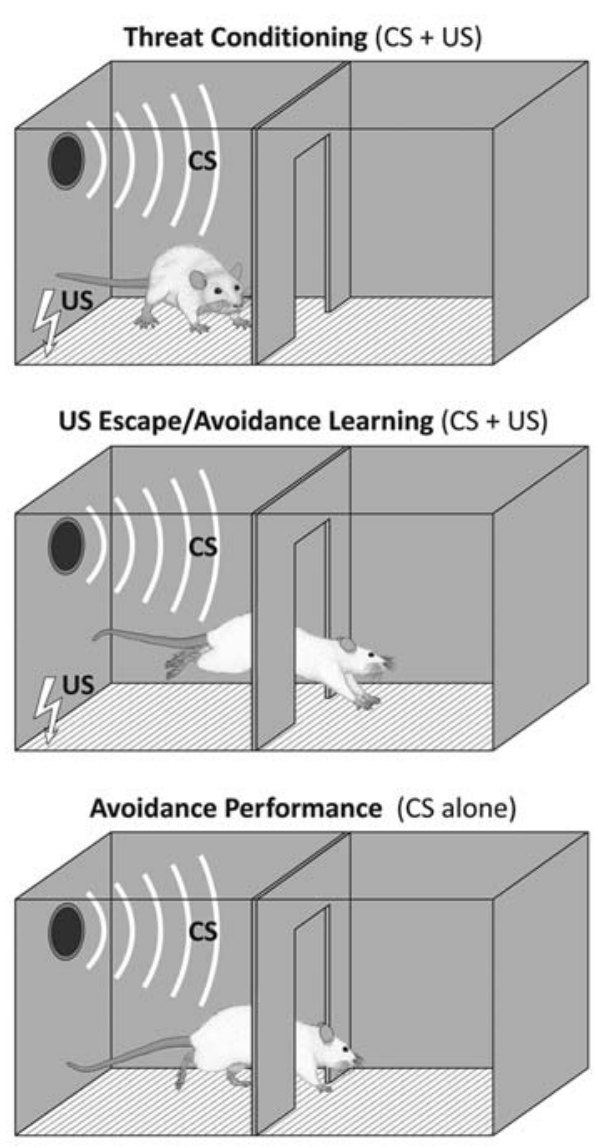

Figure 4. Signaled active avoidance. First, animals acquire an association between CS and US. Then, in subsequent trials, the animal learns that a particular behavior, such as shuttling, causes the offset of the CS and the omission of the US. In SigAA, Pavlovian and instrumental phases of learning occur in the same environment and are intermixed. Over the course of learning, animals shift from reactive freezing to active avoidance. CSevoked freezing remains suppressed, even in alternate contexts that do not allow the avoidance response.

response (usually shuttling across a divided chamber), the CS is terminated and the US is omitted. Initially, the subject freezes to the CS. But, over trials, the avoidance response is acquired and freezing is suppressed. Similar to what has been observed using EFT, lesions of LA and BA impede the expression of SigAA behavior (Choi et al. 2010), suggesting that the two forms involve a similar mechanism in which active behavior reinforced by CS termination comes to supplant reactive freezing.

CS-evoked freezing is a more potent constraint on SigAA learning than it is on EFT. This difference is likely due to the fact that the negative reinforcement phase of EFT occurs under extinction conditions, whereas the US will always follow the CS in SigAA if the subject fails to avoid. SigAA training has a tendency to produce poor performers, a notable minority of subjects that do not acquire the avoidance response because of excessive freezing (Choi et al. 2010; Lázaro-Muñoz et al. 2010; Galatzer-Levy et al. 2014). In these animals, CeA lesion produces a substantial rebound, suggesting that some 
amount of latent negative reinforcement learning occurs, but is overshadowed by CS-evoked freezing (Choi et al. 2010; Lázaro-Muñoz et al. 2010). Additionally, pretraining lesions of CeA facilitate SigAA (Moscarello and LeDoux 2013), whereas they produce no significant effect on EFT (Amorapanth et al. 2000). In spite of the inherent conflict between freezing and avoidance behavior, the majority of subjects successfully transition from reactive to active responses to the CS. Freezing remains suppressed even in contexts that do not allow the subject to perform the avoidance response (Kamin et al. 1963; Moscarello and LeDoux 2013), suggesting that SigAA training is a potent means by which conditioned aversion can be managed and inhibited. This transition is mediated by the infralimbic prefrontal cortex (ilPFC), inactivation or lesion of which enhances freezing and hinders avoidance (Moscarello and LeDoux 2013). Electrophysiological studies show an inverse relationship between activity in ilPFC and brainstem-projecting neurons in medial $\mathrm{CeA}$, suggesting that ilPFC exerts feed-forward inhibition on the cells that underpin freezing (Quirk et al. 2003; Likhtik et al. 2005).

The engagement of ilPFC seems to reorganize the defensive strategy evoked by an aversive CS. The decline of freezing that accompanies the acquisition of avoidance is not simply the replacement of one response with another. Not only does freezing remain inhibited in an environment that does not allow the avoidance response, but ilPFC also attenuates CS-elicited defecation, a physiological reaction that does not directly impede SigAA (Moscarello and LeDoux 2013). These data suggest the intriguing hypothesis that conditioned negative reinforcement learning leads to a fundamental reevaluation of learned threats. Because SigAA mitigates the reactive impact of an aversive stimulus by allowing the subjects to gain control of their environment, it nicely models active coping processes by which an internal locus of control can promote better mental health outcomes in humans (LeDoux and Gorman 2001).

In addition to serving as conditioned negative reinforcers, aversive CSs can influence action by modulating an ongoing instrumental behavior. A classic laboratory paradigm used to study the modulatory effect of a CS is called Pavlovian to instrumental transfer (PIT). In a PIT task, a previously conditioned CS is presented while the animal is performing a baseline instrumental behavior. Depending on the task, the CS will either facilitate or suppress action. In an early study, Estes and Skinner (1941) found that behavior maintained by food reinforcement was suppressed during the occurrence of an aversive CS. Initially called conditioned anxiety, and later conditioned emotional response (Hunt and Brady 1951), this phenomenon is most commonly referred to as conditioned suppression today (Bouton and Bolles 1979; Cardinal et al. 2002; Balleine and Killcross 2006). Conditioned suppression requires LA and CeA (Campese et al. 2014a) and has been interpreted as simple response competition between instrumental behavior and freezing (Kamin 1965). However, it has been shown that suppression is not fully accounted for by freezing. For example, lesions of the periaqueductal gray disrupt freezing but not suppression (Amorapanth et al. 1999). Suppression seems to involve broader behavioral effects than simple competition by freezing.

Conditioned suppression occurs when the Pavlovian CS is aversive and the instrumental reinforcer is appetitive. In contrast, conditioned facilitation occurs when the Pavlovian and instrumental elements have the same valence (Fig. 5). This has been studied extensively in appetitive conditioning. In a typical design, a CS that has been paired with food will enhance the performance of a behavior maintained by food reinforcement (Lovibond
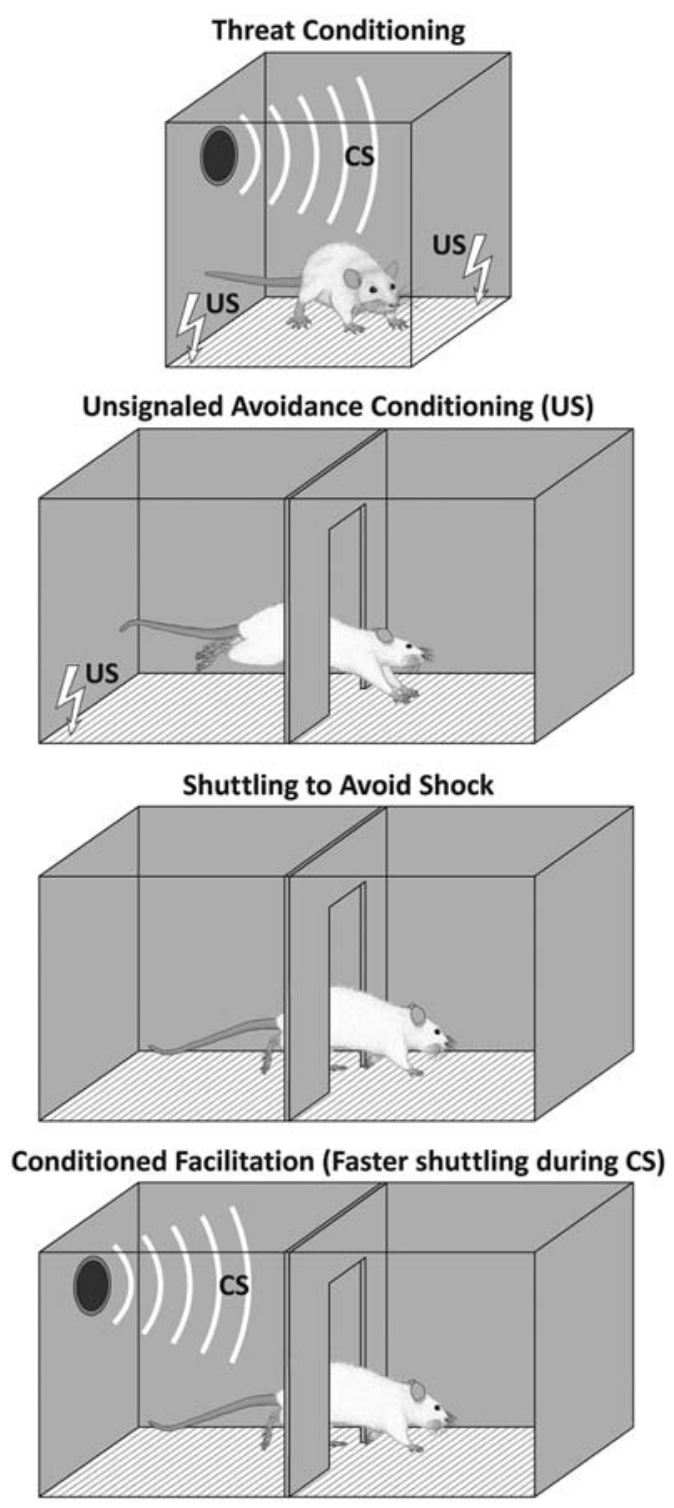

Figure 5. Pavlovian to instrumental transfer. In conditioned facilitation, animals first undergo Pavlovian threat conditioning. Then, animals learn an unsignaled active avoidance (USAA) response, in which the animal must shuttle to avoid shocks presented at a set interval. When the CS is delivered over this behavior, shuttling is strongly enhanced. This is in contrast to conditioned suppression, in which an aversive CS attenuates an appetitive action. 
1983; Holland and Gallagher 2003). A comparable aversive PIT task for rodents has recently been developed (Campese et al. 2013). Rats were given Pavlovian CSUS pairings involving a tone and a shock in one context, and then trained to shuttle back and forth in a divided chamber to avoid a shock US. The CS is presented during performance of this unsignaled active avoidance behavior (USAA), facilitating the avoidance response. A CS that has been unpaired with the US does not facilitate shuttling, suggesting that the facilitation is related to the $\mathrm{CS}-$ US association (Campese et al. 2013).

USAA behavior initially depends on LA and BA, and is constrained by CeA-mediated freezing. However, extensive training makes USAA amygdala-independent (Lázaro-Muñoz et al. 2010), allowing the amygdalar substrates of conditioned facilitation to be examined without disrupting the baseline task. Lesions of LA and CeA disrupt PIT, but BA lesions have no effect. Baseline USAA behavior is unaffected by these lesions, demonstrating that the underlying avoidance response is intact (Campese et al. 2014b). These effects on facilitation show that LA and $\mathrm{CeA}$ can control opposite and incompatible responses (freezing and shuttling) via different internal circuits and/ or output connections. Thus, freezing is the default response when threat is imminent (Fanselow and Lester 1988). However, if the CS occurs over a preexisting response that avoids shock, then facilitation occurs.

Although facilitation and freezing both involve LA and $\mathrm{CeA}$, facilitation also requires the medial amygdala (MeA; McCue et al. 2014). MeA may play a key role as an intra-amygdala link between the LA and CeA recruited specifically to produce facilitation, because past studies found no effects of MeA lesion on freezing (Nader et al. 2001). MeA receives direct inputs from the LA (Pitkänen et al. 1997) and sends projections to both medial and lateral divisions CeA (Canteras et al. 1995). It is unknown how these pathways make the switch from freezing to conditioned facilitation, though it is reasonable to hypothesize that they exert their effect via the CeA microcircuits that encode conditioned responses to the CS. Other research suggests that opposing patterns of activity in lateral CeA microcircuits can produce mutually exclusive patterns of CS-evoked behavior. Lateral CeA contains projection neurons that disinhibit cholinergic cells in the basal forebrain. When activated, these cells cause locomotion increases in response to an aversive CS (Gozzi et al. 2010). Basal forebrain-projecting lateral CeA cells contact medial CeA cells that project to PAG, allowing this population to promote motion while inhibiting cells that underpin freezing (Gozzi et al. 2010). It is not known whether this population is involved in facilitation; however, it provides a putative mechanism by which CeA can toggle between freezing and facilitation of locomotor activation.

In summary, aversive Pavlovian memory can influence and organize a variety of behaviors beyond the reactive freezing typically used as a readout of PTC. The offset of an aversive CS can negatively reinforce behavior, transitioning the animal from a reactive to an active profile of CS-evoked responses. This transition occurs as the animal toggles between functional pathways emanating from LA, with LA-CeA connections underpinning reactive behavior and LA-BA connections underpinning active instrumental response to the CS. Aversive Pavlovian memory can also modulate ongoing actions. The CS produces freezing and suppression when set against an appetitive instrumental task and facilitation when presented over an aversively motivated behavior. This suggests that the broader context of learning and memory can dramatically influence the behavioral expression of CS-US associations. Although facilitation and freezing both require LA and $\mathrm{CeA}, \mathrm{MeA}$ also plays a selective role in facilitation. The addition of MeA alters this circuit to invigorate the output of USAA behavior.

\section{CONCLUSION}

Research on PTC has revealed in great detail the system, circuit, and cellular mechanisms involved in the acquisition and storage of aversive associative memories. By following the CS through the brain, many of the pathways involved in PTC have been mapped. Importantly, a key brain region for the learning and memory in all mammals, including humans, is the amygdala. Studies in rodents have shown that synaptic plasticity occurs in LA following CS-US pairings, allowing the conditioned stimulus to flow to downstream circuitry, such as CeA. The circuitry in $\mathrm{CeA}$ encodes different elements of the reaction to the CS after conditioning. Aversive Pavlovian memory can also engage the substrates of instrumental action. LA stores critical aspects of the CS-US association used in the acquisition of new instrumental responses, and BA allows the CS to function as a conditioned negative reinforcer in the learning of an instrumental response. In contrast, the progression of information across an LA, MeA, and CeA pathway allows the CS to motivate an ongoing instrumental behavior. This work shows the power of using PTC to decipher processes underlying memory formation and learned changes in neural processing within a specific, behaviorally defined circuit.

\section{REFERENCES}

Amorapanth P, Nader K, LeDoux JE. 1999. Lesions of periaqueductal gray dissociate-conditioned freezing from conditioned suppression behavior in rats. Learn Mem 6: 491-499.

Amorapanth P, LeDoux JE, Nader K. 2000. Different lateral amygdala outputs mediate reactions and actions elicited by a fear-arousing stimulus. Nat Neurosci 3: 74-79.

Armony JL, Quirk GJ, LeDoux JE. 1998. Differential effects of amygdala lesions on early and late plastic components of auditory cortex spike trains during fear conditioning. J Neurosci 18: 2592-2601.

Balleine BW, Killcross S. 2006. Parallel incentive processing: An integrated view of amygdala function. Trends Neurosci 29: $272-279$.

Bauer EP, Schafe GE, LeDoux JE. 2002. NMDA receptors and L-type voltage-gated calcium channels contribute to longterm potentiation and different components of fear memory formation in the lateral amygdala. J Neurosci 22: 5239-5249.

Behbehani MM. 1995. Functional characteristics of the midbrain periaqueductal gray. Prog Neurobiol 46: 575-605. 
Blair HT, Schafe GE, Bauer EP, Rodrigues SM, LeDoux JE. 2001. Synaptic plasticity in the lateral amygdala: A cellular hypothesis of fear conditioning. Learn Mem 8: 229-242.

Blair HT, Tinkelman A, Moita MA, LeDoux JE. 2003. Associative plasticity in neurons of the lateral amygdala during auditory fear conditioning. Ann NY Acad Sci 985: 485-487.

Blanchard RJ, Blanchard DC. 1969. Passive and active reactions to fear-eliciting stimuli. J Comp Physiol Psychol 68: 129135.

Bouton ME, Bolles RC. 1979. Role of conditioned contextual stimuli in reinstatement of extinguished fear. $J$ Exp Psychol Anim Behav Process 5: 368-378.

Bush DE, Caparosa EM, Gekker A, Ledoux J. 2010. $\beta$-adrenergic receptors in the lateral nucleus of the amygdala contribute to the acquisition but not the consolidation of auditory fear conditioning. Front Behav Neurosci 4: 154.

Cain CK, LeDoux JE. 2007. Escape from fear: A detailed behavioral analysis of two atypical responses reinforced by CS termination. J Exp Psychol Anim Behav Process 33: 451-463.

Campese V, McCue M, Lázaro-Muñoz G, Ledoux JE, Cain CK. 2013. Development of an aversive Pavlovian-to-instrumental transfer task in rat. Front Behav Neurosci 7: 176.

Campese VD, Gonzaga R, LeDoux JE. 2014a. Facilitation and suppression of instrumental responding require connections between the lateral and central amygdala. Soc Neurosci Abstr.

Campese VD, Kim J, Lázaro-Muñoz G, Pena L, LeDoux JE, Cain CK. 2014b. Lesions of lateral or central amygdala abolish aversive Pavlovian-to-instrumental transfer in rats. Front Behav Neurosci 8: 161.

Canteras NS, Simerly RB, Swanson LW. 1995. Organization of projections from the medial nucleus of the amygdala: A PHAL study in the rat. J Comp Neurol 360: 213-245.

Cardinal RN, Parkinson JA, Hall J, Everitt BJ. 2002. Emotion and motivation: The role of the amygdala, ventral striatum, and prefrontal cortex. Neurosci Biobehav Rev 26: 321-352.

Carew TJ, Walters ET, Kandel ER. 1981. Associative learning in Aplysia: Cellular correlates supporting a conditioned fear hypothesis. Science 211: 501-504.

Charney DS. 2004. Discovering the neural basis of human social anxiety: A diagnostic and therapeutic imperative. Am J Psychiatry 161: $1-2$.

Choi JS, Cain CK, LeDoux JE. 2010. The role of amygdala nuclei in the expression of auditory signaled two-way active avoidance in rats. Learn Mem 17: 139-147.

Ciocchi S, Herry C, Grenier F, Wolff SB, Letzkus JJ, Vlachos I, Ehrlich I, Sprengel R, Deisseroth K, Stadler MB, et al. 2010. Encoding of conditioned fear in central amygdala inhibitory circuits. Nature 468: 277-282.

Davis M. 1992. The role of the amygdala in fear and anxiety. Annu Rev Neurosci 15: 353-375.

Duvarci S, Popa D, Paré D. 2011. Central amygdala activity during fear conditioning. J Neurosci 31: 289-294.

Estes WK, Skinner BF. 1941. Some quantitative properties of anxiety. J Exp Psychol 29: 390-400.

Faber ES, Delaney AJ, Power JM, Sedlak PL, Crane JW, Sah P. 2008. Modulation of SK channel trafficking by $\beta$ adrenoceptors enhances excitatory synaptic transmission and plasticity in the amygdala. $J$ Neurosci 28: $10803-10813$.

Fanselow MS. 1994. Neural organization of the defensive behavior system responsible for fear. Psychon Bull Rev 1: 429-438.

Fanselow MS, Lester LS. 1988. A functional behavioristic approach to aversively motivated behavior: Predatory imminence as a determinant of the topography of defensive behavior. In Evolution and learning (ed. Bolles RC, Beecher MD), pp. 185-212. Lawrence Erlbaum, Hillsdale, NJ.

Galatzer-Levy IR, Moscarello J, Blessing EM, Klein J, Cain CK, LeDoux JE. 2014. Heterogeneity in signaled active avoidance learning: Substantive and methodological relevance of diversity in instrumental defensive responses to threat cues. Front Syst Neurosci 8: 179.

Glanzman DL. 2010. Common mechanisms of synaptic plasticity in vertebrates and invertebrates. Curr Biol 20: R31-R36.
Gozzi A, Jain A, Giovannelli A, Bertollini C, Crestan V, Schwarz AJ, Tsetsenis T, Ragozzino D, Gross CT, Bifone A. 2010. A neural switch for active and passive fear. Neuron 67: 656-666.

Gross CT, Canteras NS. 2012. The many paths to fear. Nat Rev Neurosci 13: 651-658.

Haubensak W, Kunwar PS, Cai H, Ciocchi S, Wall NR, Ponnusamy R, Biag J, Dong HW, Deisseroth K, Callaway EM, et al. 2010. Genetic dissection of an amygdala microcircuit that gates conditioned fear. Nature 468: 270-276.

Hebb DO. 1949. The organization of behavior. Wiley, New York.

Herry C, Ciocchi S, Senn V, Demmou L, Müller C, Lüthi A. 2008. Switching on and off fear by distinct neuronal circuits. Nature 454: 600-606.

Holland PC, Gallagher M. 2003. Double dissociation of the effects of lesions of basolateral and central amygdala on conditioned stimulus-potentiated feeding and Pavlovian-instrumental transfer. Eur J Neurosci 17: 1680-1694.

$\mathrm{Hu}$ H, Real E, Takamiya K, Kang MG, Ledoux J, Huganir RL, Malinow R. 2007. Emotion enhances learning via norepinephrine regulation of AMPA-receptor trafficking. Cell 131: $160-173$.

Huber D, Veinante P, Stoop R. 2005. Vasopressin and oxytocin excite distinct neuronal populations in the central amygdala. Science 308: $245-248$.

Hunt HF, Brady JV. 1951. Some effects of electro-convulsive shock on a conditioned emotional response ("anxiety"). $J$ Comp Phsyiol Psychol 44: 88-98.

Johansen JP, Cain CK, Ostroff LE, LeDoux JE. 2011. Molecular mechanisms of fear learning and memory. Cell 147: 509-524.

Johansen JP, Diaz-Mataix L, Hamanaka H, Ozawa T, Ycu E, Koivumaa J, Kumar A, Hou M, Deisseroth K, Boyden ES, et al. 2014. Hebbian and neuromodulatory mechanisms interact to trigger associative memory formation. Proc Natl Acad Sci 111: E5584-E5592.

Kamin LJ. 1965. Temporal and intensity characteristics of the conditioned stimulus. In Classical conditioning: A symposium (ed. Prokasy W), pp. 118-147. Appleton, New York.

Kamin LJ, Brimer CJ, Black AH. 1963. Conditioned suppression as a monitor of fear of the CS in the course of avoidance training. J Comp Physiol Psychol 56: 497-501.

Kandel ER. 1997. Genes, synapses, and long-term memory. $J$ Cell Physiol 173: 124-125.

Kapp BS, Frysinger RC, Gallagher M, Haselton JR. 1979. Amygdala central nucleus lesions: Effect on heart rate conditioning in the rabbit. Physiol Behav 23: 1109-1117.

Lázaro-Muñoz G, LeDoux JE, Cain CK. 2010. Sidman instrumental avoidance initially depends on lateral and basal amygdala and is constrained by central amygdala-mediated Pavlovian processes. Biol Psychiatry 67: 1120-1127.

LeDoux JE. 2000. Emotion circuits in the brain. Annu Rev Neurosci 23: $155-184$.

LeDoux JE. 2012. Evolution of human emotion: A view through fear. Prog Brain Res 195: 431-442.

LeDoux JE. 2014. Coming to terms with fear. Proc Natl Acad Sci 111: 2871-2878.

LeDoux JE, Gorman JM. 2001. A call to action: Overcoming anxiety through active coping. Am J Psychiatry 158: 1953-1955.

LeDoux JE, Del Bo A, Tucker LW, Harshfield G, Talman WT, Reis DJ. 1982. Hierarchic organization of blood pressure responses during the expression of natural behaviors in rat: Mediation by sympathetic nerves. Exp Neurol 78: 121-133.

LeDoux JE, Iwata J, Cicchetti P, Reis DJ. 1988. Different projections of the central amygdaloid nucleus mediate autonomic and behavioral correlates of conditioned fear. J Neurosci 8: 2517-2529.

LeDoux JE, Cicchetti P, Xagoraris A, Romanski LM. 1990. The lateral amygdaloid nucleus: Sensory interface of the amygdala in fear conditioning. J Neurosci 10: 1062-1069.

Li H, Penzo MA, Taniguchi H, Kopec CD, Huang ZJ, Li B. 2013. Experience-dependent modification of a central amygdala fear circuit. Nat Neurosci 16: 332-339.

Liberzon I, Sripada CS. 2008. The functional neuroanatomy of PTSD: A critical review. Prog Brain Res 167: 151-169. 
Likhtik E, Pelletier JG, Paz R, Paré D. 2005. Prefrontal control of the amygdala. $J$ Neurosci 25: 7429-7437.

Lovibond PF. 1983. Facilitation of instrumental behavior by a Pavlovian appetitive conditioned stimulus. J Exp Psychol Anim Behav Process 9: 225-247.

Malenka RC, Nicoll RA. 1999. Long-term potentiation-A decade of progress? Science 285: 1870-1874.

Maren S, Quirk GJ. 2004. Neuronal signaling of fear memory. Nat Rev Neurosci 5: 844-852.

Maren S, Aharonov G, Stote DL, Fanselow MS. 1996. N-methyl-D-aspartate receptors in the basolateral amygdala are required for both acquisition and expression of conditional fear in rats. Behav Neurosci 110: 1365-1374.

Maren S, Yap SA, Goosens KA. 2001. The amygdala is essential for the development of neuronal plasticity in the medial geniculate nucleus during auditory fear conditioning in rats. J. Neurosci 21: RC135.

McCue MG, LeDoux JE, Cain CK. 2014. Medial amygdala lesions selectively block aversive Pavlovian-instrumental transfer in rats. Front Behav Neurosci 8: 329.

Milad MR, Quirk GJ. 2012. Fear extinction as a model for translational neuroscience: Ten years of progress. Annu Rev Psychol 63: 129-151.

Moscarello JM, LeDoux JE. 2013. Active avoidance learning requires prefrontal suppression of amygdala-mediated defensive reactions. $J$ Neurosci 33: 3815-3823.

Nader K, Majidishad P, Amorapanth P, LeDoux JE. 2001. Damage to the lateral and central, but not other, amygdaloid nuclei prevents the acquisition of auditory fear conditioning. Learn Mem 8: 156-163.

Ohman A, Mineka S. 2001. Fears, phobias, and preparedness: Toward an evolved module of fear and fear learning. Psychol Rev 108: 483-522.

Paré D, Collins DR. 2000. Neuronal correlates of fear in the lateral amygdala: Multiple extracellular recordings in conscious cats. J Neurosci 20: 2701-2710.

Parsons RG, Ressler KJ. 2013. Implications of memory modulation for post-traumatic stress fear disorders. Nat Neurosci 16: $146-153$.

Penzo MA, Robert V, Li B. 2014. Fear conditioning potentiates synaptic transmission onto long-range projection neurons in the lateral subdivision of central amygdala. J Neurosci 34: 2432-2437.

Phelps EA. 2006. Emotion and cognition: Insights from studies of the human amygdala. Annu Rev Psychol 57: 27-53.

Pitkänen A, Savander V, LeDoux JE. 1997. Organization of intra-amygdaloid circuitries in the rat: An emerging framework for understanding functions of the amygdala. Trends Neurosci 20: 517-523.
Quirk GJ, Repa C, LeDoux JE. 1995. Fear conditioning enhances short-latency auditory responses of lateral amygdala neurons: Parallel recordings in the freely behaving rat. Neuron 15: 1029-1039.

Quirk GJ, Armony JL, LeDoux JE. 1997. Fear conditioning enhances different temporal components of tone-evoked spike trains in auditory cortex and lateral amygdala. Neuron 19: 613-624.

Quirk GJ, Likhtik E, Pelletier JG, Paré D. 2003. Stimulation of medial prefrontal cortex decreases the responsiveness of central amygdala output neurons. J Neurosci 23: 8800 8807.

Raman IM, Tong G, Jahr CE. 1996. $\beta$-adrenergic regulation of synaptic NMDA receptors by cAMP-dependent protein kinase. Neuron 16: 415-421.

Rauch SL, Shin LM, Phelps EA. 2006. Neurocircuitry models of posttraumatic stress disorder and extinction: Human neuroimaging research-Past, present, and future. Biol Psychiatry 60: $376-382$

Repa JC, Muller J, Apergis J, Desrochers TM, Zhou Y, LeDoux JE. 2001. Two different lateral amygdala cell populations contribute to the initiation and storage of memory. Nat Neurosci 4: 724-731.

Rodrigues SM, Schafe GE, LeDoux JE. 2001. Intra-amygdala blockade of the NR2B subunit of the NMDA receptor disrupts the acquisition but not the expression of fear conditioning. $J$ Neurosci 21: 6889-6896.

Romanski LM, Clugnet MC, Bordi F, LeDoux JE. 1993. Somatosensory and auditory convergence in the lateral nucleus of the amygdala. Behav Neurosci 107: 444-450.

Sullivan GM, Apergis J, Bush DE, Johnson LR, Hou M, Ledoux JE. 2004. Lesions in the bed nucleus of the stria terminalis disrupt corticosterone and freezing responses elicited by a contextual but not by a specific cue-conditioned fear stimulus. Neuroscience 128: 7-14.

Tully K, Bolshakov VY. 2010. Emotional enhancement of memory: How norepinephrine enables synaptic plasticity. Mol Brain 3: 15.

Tully K, Li Y, Tsvetkov E, Bolshakov VY. 2007. Norepinephrine enables the induction of associative long-term potentiation at thalamo-amygdala synapses. Proc Natl Acad Sci 104: 14146-14150.

Viviani D, Stoop R. 2008. Opposite effects of oxytocin and vasopressin on the emotional expression of the fear response. Prog Brain Res 170: 207-218.

Viviani D, Charlet A, ven den Burg E, Robinet C, Hurni N, Abatis M, Magara F, Stoop R. 2011. Oxytocin selectively gates fear responses through distinct outputs from the central amygdala. Science 333: 104-107. 


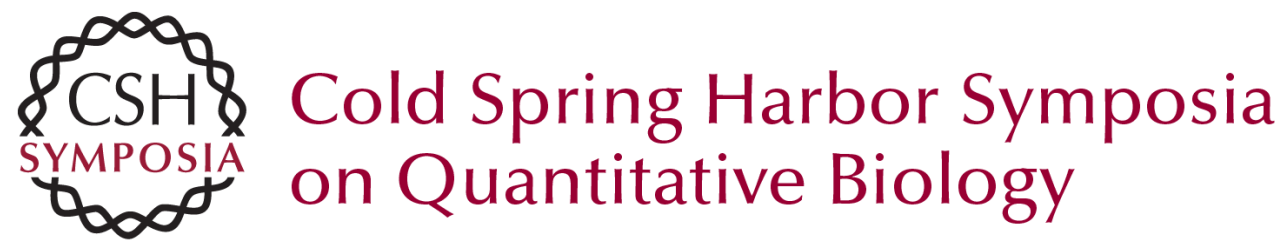

\section{Diverse Effects of Conditioned Threat Stimuli on Behavior}

Justin M. Moscarello and Joseph LeDoux

Cold Spring Harb Symp Quant Biol 2014 79: 11-19 originally published online February 19, 2015 Access the most recent version at doi:10.1101/sqb.2014.79.024968

References This article cites 79 articles, 24 of which can be accessed free at: http://symposium.cshlp.org/content/79/11.full.html\#ref-list-1

\section{License}

Email Alerting Receive free email alerts when new articles cite this article - sign up in Service the box at the top right corner of the article or click here. 